\title{
Counterfeit patronage: human values, counterfeit experience and construal level
}

\author{
Xuemei Bian $^{1} \cdot$ Yanisa Tantiprapart $^{2} \cdot$ George Chryssochoidis $^{2}$ (D) $\cdot$ Kai-Yu Wang $^{3}$
}

Accepted: 12 November 2021 / Published online: 19 November 2021

(C) The Author(s) 2021

\begin{abstract}
Counterfeit-related studies have revealed motivational drives for counterfeit consumption. Little is known concerning the implications of consumers' enduring and normative beliefs about proper standards of conduct as the determinants of counterfeit patronage. Drawing on the Schwartz theory of human values, experience literature and construal level theory, this research investigates counterfeit patronage by addressing three crucially important questions: (1) what personal values determine counterfeit patronage; (2) how do these relationships vary as a function of counterfeit experience and (3) how do values have power in eliminating counterfeit consumption? Two studies provide robust evidence that self-transcendence values mitigate counterfeit patronage when consumers' counterfeit experience is low. We also demonstrate that consumers who endorse self-transcendence values more exhibit higher levels of construal, which results in reduced counterfeit patronage.
\end{abstract}

Keywords Counterfeits $\cdot$ Human values theory $\cdot$ Counterfeit patronage $\cdot$ Counterfeit experience $\cdot$ Construal level

George Chryssochoidis

G.Chryssochoidis@kent.ac.uk

Xuemei Bian

xuemei.bian@northumbria.ac.uk; xuemeibian1@yahoo.com

Yanisa Tantiprapart

tyanisa22@gmail.com

Kai-Yu Wang

kwang@brocku.ca

1 Newcastle Business School, Northumbria University, Newcastle Upon Tyne NE1 8ST, UK

2 Business School, University of Kent, Kent CT2 7NZ, UK

3 Goodman School of Business, Brock University, Niagara Region, 1812 Sir Isaac Brock Way,

St. Catharines, ON L2S 3A1, Canada 


\section{Introduction}

Counterfeits have become a significant and impactful economic phenomenon (Bian, 2018). According to estimations from the European Union Intellectual Property Office (2016), the value of counterfeit and pirated products in the global market in 2013 accounted for $2.5 \%$ of world trade. The global value of trade in counterfeit and pirated products has seen an unprecedented increase in recent years and is worth a staggering half a trillion US dollars a year (Organisation of Economic Co-operation and Development 2016).

Various anti-counterfeiting measures, including diligent legal litigation, are often implemented to combat counterfeiting (Herstein et al., 2015). Nevertheless, counterfeiting continues to thrive (Bian, 2018). Some researchers assert that consumer demand for counterfeits is a leading cause of the escalation of the counterfeit market (Wilcox et al., 2009). Why consumers demand and willingly purchase counterfeits has attracted much research attention. Prior studies have identified both product (Tom et al. 1998) and brand features (Marticotte \& Arcand, 2017) which draw consumers to counterfeits. Motives for counterfeit consumption have also been uncovered. For example, Bian et al. (2016) demonstrate that desire for counterfeits hinges on psychologically oriented motives ("thrill of the hunt", being part of a "secret society" and satisfying genuine interest). Focusing on the socially oriented motives, Wilcox et al. (2009) instead reveal that consumers' demand for counterfeits is greater when their luxury brand attitudes serve a social-adjustive (e.g. to fit in) rather than value-expressive function (e.g. to express themselves).

A clear and actionable understanding as to when and what personal values from Schwartz's framework determine demand for counterfeit remains elusive. This knowledge gap is surprising as personal values, the normative beliefs about proper standards of conduct (Williams 1979), serve as the basis for the development of attitudes that lead to specific decisions and predict behaviours (Hilton, 2003). In the light of this knowledge gap and significance of personal values, our objectives are (1) to understand the implications of personal values as the determinants of counterfeit patronage, (2) to gain insights into how the effect of personal values varies across consumers of different counterfeit experiences and (3) to reveal underlying mechanisms of the value effect through testing the mediating role played by the construal level (Trope \& Liberman, 2010).

Personal values from Schwartz's framework and consumption represent a fastemerging research area. Studies include values held by consumers (Wiedmann et al., 2009), values and consumer well-being (Burroughs \& Rindfleisch, 2002) and consumers' values and ethical consumption (Doran, 2009; Stringer et al., 2020). Prior research reports that consumer decisions concerning ethical consumption differ depending upon the values held by the decision-maker (Doran, 2009). Taking the lens of the seminal value theories (Schwartz \& Bilsky, 1987), this research provides new insights into the salient determinants of counterfeit patronage. The findings will enrich counterfeit-related literature where research recognises the unethical aspect of counterfeit consumption such as Bian et al. 
(2016), who document the neutralisation strategies adopted by consumers in decision-making concerning unethical consumption behaviour, and Wilcox et al. (2009), who find that counterfeit purchase tendency varies with consumers' moral beliefs about counterfeits only when their luxury brand attitudes serve a valueexpressive function.

Drawing on the experience literature (Bagozzi, 1981), this research advances knowledge (e.g. Yoo \& Lee, 2012) through unveiling the effects of personal values that vary depending on counterfeit experience. Moreover, diverging from the extant literature ascertaining motivational drives for counterfeit consumption, this research provides new insights, specifically the mediational role played by construal level which underlies the relationships between personal values and counterfeit patronage.

\section{Literature}

\subsection{Counterfeits and the scope of this research}

According to the Scrivener Regulation, counterfeits are products bearing a trademark that is identical to, or indistinguishable from, a trademark registered to another party and infringes the rights of the holder of the trademark. This definition, covering the legal perspective, is commonly adopted by researchers and has gained predominant acceptance and, thus, is used to inform this research. Research distinguishes three types of counterfeit, namely deceptive, non-deceptive (Grossman $\&$ Shapiro, 1988) and blur counterfeit (Bian, 2006). This research focuses on nondeceptive counterfeits because this form of counterfeit represents a conscious and willing decision-making process concerning consumption behaviour. Non-deceptive counterfeits are products bought when consumers are fully aware of the non-genuine nature.

\subsection{Human values and behaviour}

Human values, the 'concepts or beliefs related to desires and states' (Schwartz \& Bilsky, 1987, p. 551), are formed through both individual socialisation and unique learning experiences over time (Muncy \& Vitell, 1992). The theory of human values arranges ten core value types into a higher order, four-dimensional circumplex according to their interrelationships. This four-dimensional circular structure is oriented by two axes: (1) self-transcendence versus self-enhancement and (2) openness to change versus conservation. The self-transcendence dimension, in the opposite direction to the self-enhancement, contrasts the values of acceptance of others as equals and concern for others' welfare with those that emphasise one's own success and dominance over others. Openness to change, opposing conservation, stresses independent thought, action and changes, whereas conservation emphasises selfrestriction, traditional practice preservation and stability protection.

The human values theory has far-reaching efficacy and is widely adopted in understanding behaviour as values serve as the basis from which attitudes develop 
and behaviour is directed (Hilton, 2003). Marketing literature also provides substantial empirical evidence that personal values explain and guide consumer behaviour. For example, Krystallis et al. (2012) demonstrate that personal values are applicable to segment consumer markets of organic food and high-quality products. Consumer research reveals a strong relationship between personal values and ethical consumption, including fair trade consumption (Doran, 2009), pro-environmental behaviour (Dietz et al., 2002) and ethical-/fast-fashion consumption (Manchiraju \& Sadachar, 2014; Stringer et al., 2020). Extending the understanding of role personal values played in ethical consumer behaviour, this research explores what personal values determine counterfeit patronage.

\subsection{Counterfeit experience as a moderator}

Counterfeits have become increasingly more accessible. Accompanying this increasing accessibility, most consumers have had experience of counterfeits one way or another and might have become more acquainted with counterfeits (Bian, 2018). Two important research questions which are also highly relevant to practitioners deserve research attention: (1) does counterfeit experience eliminate acceptance of the real brands, and (2) will counterfeit experience affect counterfeit patronage? Extant studies (Nia \& Zaichkowsky, 2000; Yoo \& Lee, 2012) have partially addressed the former; hence, this research tackles the latter.

Individuals learn through experience and experience modifies individuals profoundly in a way that, after having crossed, endured and traversed it, they will never be the same again (Roth \& Jornet, 2014). Although remaining under-theorised (Wong et al., 2001), the concept of experience plays a critical role in the formation of theories, including the experiential learning theory and attitude theories. For example, perceived behavioural control, the key attribute of the theory of planned behaviour (Ajzen, 1991), is assumed to reflect past experience additional to anticipated difficulties or facilitating conditions. Marketing literature reports that experience heavily influences the current and future shopping patterns of consumers (Bagozzi, 1981).

Counterfeit evaluations of more experienced consumers are more positive than less experienced consumers (Penz \& Stöttinger, 2008). Nia and Zaichkowsky (2000) report that the attitude towards counterfeits of consumers who buy counterfeits is more positive than consumers who do not purchase. Diverging from extant studies which focus on possible direct impact, we propose a novel moderating effect of counterfeit experience on the relationship between personal values and counterfeit patronage. We acknowledge the arguments that, benefitting from the advancement of technology in recent years, the quality of counterfeits has significantly improved (Wilcox et al., 2009). Consumers with more experience of counterfeits are likely to recognise that their functionalities (at least for some product categories) are similar to the authentic product (Bian et al., 2016); thus, they might develop a positive attitude towards counterfeits (de Matos et al., 2007). We, however, argue that the prominent psychologically oriented motives for counterfeit consumption, such as the "thrill of the hunt" and satisfying own interest (Bian et al., 2015), would diminish 
with experience. Although psychologically oriented motives and the attitude towards counterfeits may exhibit a combined effect when counterfeit experience is low, the former, which underscores predicted affective gains, would outperform the latter (the resultant outcome of cognitive judgments). The theory of affective primacy (Zajonc, 1980), which theorises the predominant prepotency of affect over cognition in determining subsequent responses, lends support. In contrast, because psychologically oriented motives will disappear with counterfeit experience, when counterfeit experience is high, the effects of attitude will prevail. Therefore, the influence of personal values on counterfeit patronage depends on the level of counterfeit experience.

\subsection{Construal level as a mediator}

We propose a mediational effect of construal level, such that personal values define how one construes the world, namely abstract- versus concrete-oriented thinking which, in turn, impacts counterfeit patronage. Construal level theory, coined by Trope and Liberman (2010), asserts that abstract versus concrete thinking is determined, in large, by psychological distance. If an event is psychologically far (proximal), an abstract (concrete) construal would manifest. Self-transcendence values express a growth motivation and reflect care for others' well-being over self-interests and help to build and maintain relations (Schwartz, 2015), all of which, according to construal level theory, evoke psychologically distant representations. We, thus, expect that individuals who endorse self-transcendence values more are more likely to exhibit higher levels of construal. How one construes the world can determine in part how one behaves. A more abstract processing style (higher construal level) is more likely to facilitate the pursuit of long-term goals over short-term gains (Fujita et al., 2006), such as immediate gratifications associated with counterfeits. Therefore, consumers' construal level exerts a negative influence on counterfeit patronage.

\subsection{Overview}

We conducted two studies. Study 1 investigates how values and their interaction with counterfeit experience influence counterfeit patronage. Study 2 validates Study 1 's findings using a specific branded product and rules out potential issues related to using a general measure in Study 1 (Le Roux et al., 2019). Study 2 also explores how self-transcendence values determine counterfeit patronage through unveiling the mediational effect of construal level.

\subsection{Study 1}

\subsubsection{Data collection and sample}

Data were collected from Thai consumers, to whom counterfeits are openly accessible. Thailand is one of the top 10 countries where counterfeits are widely available (International Anti-Counterfeiting Coalition 2014). Thailand remains on the priority watch-list of the International Intellectual Property Alliance for counterfeits, and 
that happens for many years in the row (U.S. Department of Homeland Security, Intellectual Property Rights Seizures Statistics 2015).

A pre-test with ten Thai consumers was conducted to eliminate possible administrative issues with data collection and to safeguard the translation accuracy of the research instrument. Three hundred usable questionnaires were then collected from randomly selected Thai consumers (aged between 19 and 54, income between less than THB10,000 and above THB200,000 per month, 150 males). Data collection was conducted throughout the day, across all weekdays, and over a period of 14 days in the marketplace. Considering consumers tend to confuse counterfeit with piracy and imitation (Bian, 2016), to eliminate confusion and to ensure data reliability, the Scrivener Regulation definition of counterfeit (see the Literature section for details) was presented at the beginning of the questionnaire. To minimise the possible effect of impression management on quality of data, respondents were informed that some consumers knowingly purchase counterfeits. This approach, recommended by Churchill (1999), is deemed to induce a respondent's admission of potentially embarrassing behaviour and, thus, is appropriate and necessary because Tai consumers are conscious of social norms and have a high tendency to avoid social embarrassment (Hendon 1999).

\subsubsection{Measures}

This research employs the European Social Survey version (ESS) of Schwartz's (2003) Portrait Values Questionnaire (PVQ) to assess personal values. The ESS is a shorter version of PVQ and is more concise and easier to understand (Davidov et al., 2008); thus, it is suitable for subjects with little or limited education (some respondents of this research only have primary school level of education). The ESS has been widely tested for cross-culture compatibility not only within European contexts (Davidov et al., 2008) but, more importantly, in Asian contexts (Perrea et al., 2014) where the internal consistency (Cronbach's alphas $>0.07$ ), according to Cortina (1993), is acceptable.

The dependent variable of behavioural patronage was measured using a two-item scale ("I am interested in counterfeits" and "I have the intention to purchase counterfeit", $r=0.88, p<0.001$ ) adapted from Silvia (2006). Counterfeit experience, the moderator, was assessed using one open question, "How many counterfeits did you have in the last two years?" This measure captured the experience in counterfeits acquired both intentionally and accidentally/not purposely. Personal information was also collected. All multi-item scales were assessed using a seven-point Likert format $(1=$ strongly disagree; $7=$ strongly agree). When necessary, scores were reverse-coded and values of items were averaged.

\subsubsection{Assessment of value measurement}

A first- and second-order confirmatory factor analysis (CFA) on the value statements was conducted. The CFA results for the individual items produced excellent fit indices, $\chi^{2} / d f=227.85$, root mean square error of approximation $($ RMSEA) $=0.06$, comparative fit index $(\mathrm{CFI})=0.95$, non-normed fit index $(\mathrm{NNFI})=0.92$, standardised 
root mean square residual $(\mathrm{SRMR})=0.04$. One item ("Important to be rich, have money and expensive things") was dropped due to a low loading (0.31), all other items were retained given loadings exceeded the 0.50 threshold (Chin 1998). The second-order four-dimensional structure of values was then tested. The fourdimensional structure fit indices are $\chi^{2} / d f=600.81$, RMSEA $=0.09, \mathrm{CFI}=0.80$, $\mathrm{NNFI}=0.78, \mathrm{SRMR}=0.11$. There is evidence that the underlying circumplex nature of the values' system affects the correlation matrix when evaluating fit (Tracey 2000). Nonetheless, the standardised loadings are excellent $(>0.80)$, the $R^{2}$ of the explained latent values are high (between 0.63 and 0.78 ), and the average variances extracted $(>0.72)$ and composite reliabilities $(>0.84)$ exceed conventional criteria (Fornell and Larker 1981).

Cronbach alpha values (between 0.63 and 0.79 ) of the four dimensions are acceptable (Cortina, 1993). All item-to-values and values-to-domains loadings are significant $(p<0.01)$, meeting the criterion of convergent validity (Bagozzi et al., 1991). The average variance extracted exceeds the squared correlations between all pairs of constructs, which indicates discriminant validity (Fornell and Lacker 1981). The overall results denote sufficient reliability and validity.

\subsubsection{Results}

SPSS AMOS 24 path analysis was run. All variables were standardised, and input variables were allowed to correlate in the path model. The measures of overall fit generally met conventional standards, which suggests the moderated model fit the data well (counterfeit experience moderated model: $\chi^{2} / d f=4.54$, RMSEA $=0.00$, $\mathrm{NFI}=0.99$, and $\mathrm{CFI}=1.00$ ).

Table 1 reports the parameter estimates of the basic model. The results confirm a strong negative relationship between self-transcendence value and counterfeit patronage $(\beta=-0.37, t=-3.53, p<0.001)$. Self-enhancement $(\beta=0.08$, $t=0.89, p=0.37)$, conservation $(\beta=0.08, t=0.73, p=0.47)$ and openness to change $(\beta=0.12, t=1.33, p=0.18)$ values, however, do not have a significant effect, which suggests that ceteris paribus, self-enhancement, conservation and openness to change values do not directly explain counterfeit patronage.

Table 1 Results of the basic model

\begin{tabular}{cllll}
\hline Basic Model & Variables & \multicolumn{2}{l}{$\begin{array}{l}\text { Value dimension } \rightarrow \text { counterfeit } \\
\text { patronage }\end{array}$} \\
\cline { 3 - 5 } & & $\begin{array}{l}\text { Stand- } \\
\text { ardised } \\
\text { estimates }\end{array}$ & $t$-value & $p$ value \\
& & & \\
\hline & Self-transcendence & $-.37 * *$ & -3.53 & .00 \\
& Self-enhancement & .08 & .89 & .37 \\
& Conservation & .08 & .73 & .47 \\
& Openness to change & .12 & 1.34 & .18 \\
\hline${ }^{*} p<.05 ; * * p<.01$ & & &
\end{tabular}


The results indicate a moderating effect of counterfeit experience on the relationship between self-transcendence value and counterfeit patronage $(\beta=1.72, t=2.27$, $p=0.02$ ). The interaction was plotted. Figure 1 suggests that when counterfeit experience is low, self-transcendence value lessens counterfeit patronage. A high level of counterfeit experience diminishes the negative effect of self-transcendence value on counterfeit patronage. Counterfeit experience does not moderate relationships between other values and counterfeit patronage $(p>0.10)$.

One point worth noting is that the results of this moderation model also suggest a negative and direct relationship between counterfeit experience and counterfeit patronage $(\beta=-1.62, t=-2.14, p=0.03)$. This result, although not in agreement with Penz and Stöttinger (2008) which implies that consumers with more experience of counterfeits are more inclined to purchase counterfeits, is likely caused by diminished psychologically oriented motives for counterfeits with experiences, such as thrill of hunt and satisfying own interest (Bian et al., 2016). Table 2 reports the parameter estimates of the moderated model of counterfeit experience. Possible effects of demographic variables were also tested, but the results were insignificant.

In study 1 , we did not specify brand or product. Using a specific brand and product, study 2 was conducted to replicate the findings of study 1 in order to show the robustness of the findings and discover the underlying mechanism as well as rule out alternative explanations.

\subsection{Study 2}

\subsubsection{Pre-test}

A pre-test of 574 Thai consumers (from the same target population of study 1) was conducted to select the brand and product category to be tested in study 2 . Nike

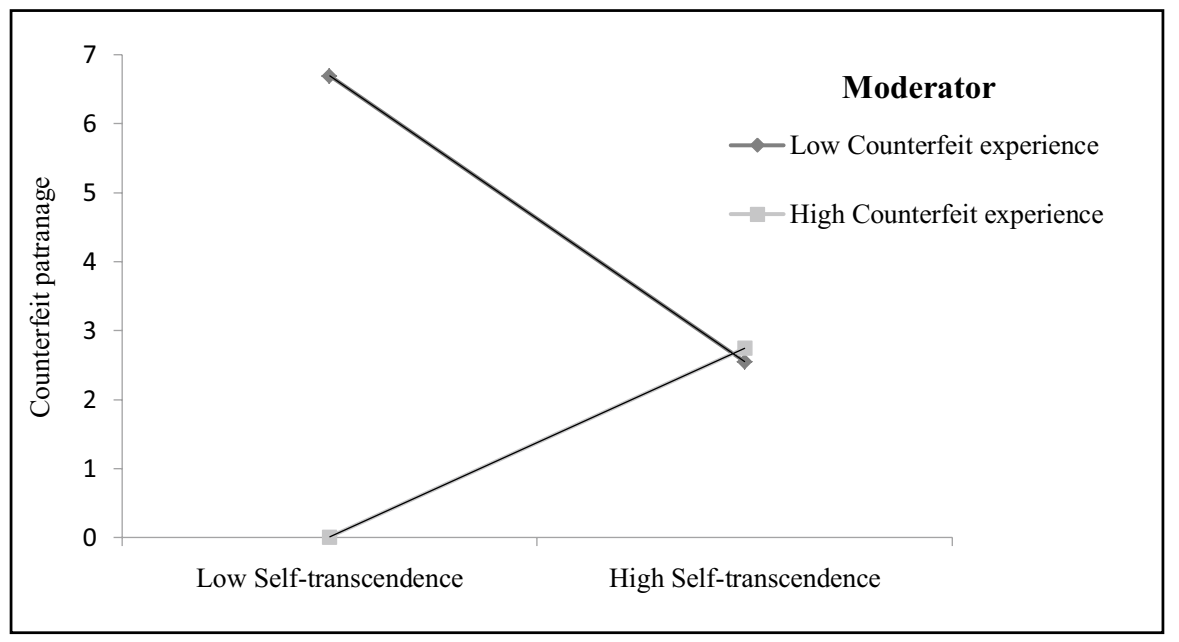

Fig. 1 Moderating effects of counterfeit experience 
Table 2 Results of the moderated model (counterfeit experience)

\begin{tabular}{lllll}
\hline Moderated model & Variables & \multicolumn{2}{l}{ Value dimension $\rightarrow$ counterfeit patronage } \\
\cline { 3 - 4 } & & $\begin{array}{l}\text { Standardised esti- } \\
\text { mates }\end{array}$ & $t$-value & $p$ value \\
\hline Self-transcendence & $-.35^{* *}$ & -4.13 & .00 \\
& $\begin{array}{l}\text { Openness to change } \\
\text { Counterfeit experience }\end{array}$ & $-160^{*}$ & 2.03 & .04 \\
$\begin{array}{l}\text { Counterfeit experience } \times \text { self- } \\
\text { transcendence }\end{array}$ & $1.72^{*}$ & -2.14 & .03 \\
\end{tabular}

${ }^{*} p<.05 ; * * p<.01$

shoes were selected for three main reasons: (1) the majority of consumers believed Nike is among the most heavily counterfeited brands ( $>73 \%)$, (2) consumers $(>55 \%)$ confirmed that counterfeit Nike shoes are openly available in the marketplace, and (3) $37.8 \%$ of consumers had one or more counterfeits of this brand.

\subsubsection{Main study}

Four hundred and eighty Thai consumers (60.2\% aged $25-44 ; 45.2 \%$ male) were recruited online (https://yimresearch.net/). They were asked to imagine that they go shopping and see a pair of Nike shoes which appeal to them. It is a counterfeit version but designed to look exactly like the genuine version and sold at a price they can afford. They were then asked to indicate counterfeit purchase intention, followed by self-transcendence, counterfeit experience, moral beliefs about counterfeit consumption, feelings of fun and excitement and construal level. Demographic information was subsequently obtained.

\subsubsection{Measures}

Counterfeit purchase intention was measured on a seven-point scale $(1=$ definitely not purchase, $7=$ definitely purchase) (Wilcox et al., 2009). Consistent with study 1 , self-transcendence was captured using five items from ESS (Cronbach's $\alpha=0.74$ ), and counterfeit experience was assessed using the item adopted in study 1. Moral beliefs about counterfeit consumption were measured using a three-item sevenpoint semantic differential scale (e.g. people who purchase counterfeit products are: $1=$ "immoral," 7 = "moral", Cronbach's $\alpha=0.87$ ) while the feeling of fun and excitement was measured on a two-item semantic differential scale (e.g. counterfeit consumption is: $1=$ "not fun," $7=$ "fun", $r=0.87$ ) (Wilcox et al., 2009). Construal level was measured using the 10-item Behavioural Identification Form (Slepian et al., 2015). For each item, respondents read about an action (e.g. picking an apple) and were asked to choose between two alternatives that more appropriately described the action. One of the alternatives corresponded to a more concrete identification and emphasised the means of the action (e.g. pulling an apple off a branch), whereas the 
other alternative was a more abstract identification and emphasised the end of an action (e.g. getting something to eat). The proportion of the abstract choices served as a measure of construal level. A higher proportion of the abstract identifications represented a higher construal level.

\subsubsection{Results}

Model 5 (5000 bootstrapping) of the Hayes PROCESS macro was used to test the model (independent variable: self-transcendence, dependent variable: counterfeit purchase intention, mediator: construal level, moderator: counterfeit experience, covariates: moral beliefs and feelings of fun and excitement). The results showed that self-transcendence negatively influenced counterfeit purchase intention $(\beta=-0.38, t=-3.27, p=0.001)$ and positively influenced construal level $(\beta=0.019, t=2.07, p=0.04)$. Construal level negatively influenced counterfeit purchase intention $(\beta=-0.78, t=-2.41, p=0.02)$. Counterfeit experience exhibited a negative but insignificant effect on counterfeit purchase intention $(\beta=-0.09$, $t=-0.43, p>0.05)$. Moral beliefs $(\beta=0.20, t=2.82, p=0.01)$ and feelings of fun and excitement $(\beta=0.24, t=3.96, p=0.00)$ positively influenced counterfeit purchase intention. The interaction effect of self-transcendence and counterfeit experience on counterfeit purchase intention was marginally significant $(\beta=0.09, t=1.89$, $p=0.06$ ). Specifically, when counterfeit experience was low and moderate, selftranscendence exerts significant negative effect on counterfeit purchase intention

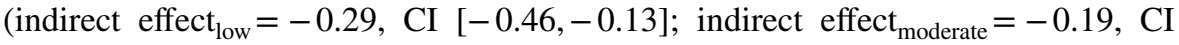
$[-0.32,-0.07])$. When counterfeit experience was high, the effect of self-transcendence on counterfeit purchase intention was insignificant (indirect effect high $=-0.07$, CI $[-0.25,0.10])$. In support of the mediational effect of construal level, the indirect effect of self-transcendence on counterfeit purchase intention was significant (index $=-0.0145$, CI $[-0.0346,-0.0007])$.

Using a specific brand and product, study 2 replicates the findings of study 1 and reveals the mediating role played by construal level in explaining the influence of self-transcendence on counterfeit purchase intention.

\section{Discussion}

This research generates novel findings as we reveal that self-transcendence values (but not other values) lessen counterfeit patronage. This effect is pronounced when consumers have low counterfeit experience. High counterfeit experience, however, mitigates the negative influence of self-transcendence values. We also identify construal level as the underlying mechanism which explains the negative effect of self-transcendence on counterfeit patronage. Additionally, our findings do not support the commonly shared concern of practitioners; that is, counterfeit experience increases counterfeit patronage. 


\subsection{Theoretical implications}

This research contributes to the personal value and unethical consumption behaviour literature through unveiling the determinant roles played by personal values in explaining counterfeit consumption. Marketing literature provides empirical evidence to the notion that personal values significantly influence ethical consumption behaviour (Doran, 2009). To the best of our knowledge, until this current research, understanding of how personal values may dictate counterfeit consumption remains scarce despite personal values serving as the basis to predict behaviour (Hilton, 2003). Our findings particularly draw attention to the importance of self-transcendence in counterfeit consumption.

This research is also one of the first which sheds light on the moderating effect of counterfeit experience regarding the relationship between personal values and counterfeit patronage, thereby advancing the knowledge concerning the impact of counterfeit experience in purchase decisions.

Diverging from extant literature investigating motives for counterfeit consumption (Bian et al., 2016; Wilcox et al., 2009), this research provides new insights into the linkages between the normative standard of behaviour, cognitive mindset and counterfeit consumption. It represents one of the few which identifies personal values as an antecedent of the construal that consumers employ to make purchase decisions, thereby enriching the understanding of elements that influence construal (Trope \& Liberman, 2010).

\subsection{Practical implications}

The findings of this research afford two pragmatic strategies. First, marketing endeavour needs to be placed in elevating the self-transcendence values (but not other personal values) since they have prominent power in reducing counterfeit patronage. Specifically, businesses could develop and deliver educational programmes jointly with schools, with the aim of enhancing the self-transcendence values of adolescents as adolescence is a key period for the formation of personal values which are developed over time and, once developed, are relatively stable (Muncy \& Vitell, 1992).

Second, our findings suggest that strategies aiming to eliminate demand for counterfeits through exposing consumers to counterfeits and offering counterfeit trials, a typical behavioural influence approach, would need to be applied with caution. For example, Impact Planet, a charity in the UK, offers consumers opportunities to try and test a wide range of counterfeits. According to our findings, counterfeit experiences, although unlikely to increase counterfeit patronage directly, would eliminate the negative effect of self-transcendence on counterfeit consumption. Thus, counterfeit trials might not cast desirable outcomes.

\subsection{Limitations and future research}

This research has several limitations which offer avenues for further research. First, we captured overall counterfeit experience rather than specific experience obtained 
either intentionally or unintendedly. Disentangling the impact (both direct and indirect) of distinct counterfeit experiences represents an area of potential implications. Second, why some personal values do not explain counterfeit patronage is a challenging question that deserves research attention. Previous research shows that low (vs. high) self-esteem consumers tend to purchase inferior products (Stuppy et al., 2020). Future research could identify how internal factors (e.g., self-esteem) influence counterfeit patronage when consumers hold different personal values.

Third, although not the focus of this research, the finding concerning the main effect of counterfeit experience which denies the commonly shared concern of practitioners, that is counterfeit experience, increases counterfeit patronage and, no doubt, inspires further debate. One possible explanation for this surprising finding is that the prominent allure pertaining to counterfeits, such as the "thrill of the hunt" and satisfying own interest (Bian et al., 2016), is likely to diminish when counterfeits become easily accessible which, in turn, neutralises or substantially reduces demand. Thus, exploring influences of counterfeit experience on motives for counterfeit consumption represents an area of potential because this effort would probably dissect the seemingly inconclusive findings pertaining to the impact of counterfeit experience on consumer response. Finally, this research is limited to Thai consumers. A study across cultures might reveal intercultural differences that are relevant to heavily counterfeited global brands.

\section{Declarations}

Ethics approval Obtained

Conflict of interest The authors declare no competing interests.

Open Access This article is licensed under a Creative Commons Attribution 4.0 International License, which permits use, sharing, adaptation, distribution and reproduction in any medium or format, as long as you give appropriate credit to the original author(s) and the source, provide a link to the Creative Commons licence, and indicate if changes were made. The images or other third party material in this article are included in the article's Creative Commons licence, unless indicated otherwise in a credit line to the material. If material is not included in the article's Creative Commons licence and your intended use is not permitted by statutory regulation or exceeds the permitted use, you will need to obtain permission directly from the copyright holder. To view a copy of this licence, visit http://creativecommons.org/licen ses/by/4.0/.

\section{References}

Ajzen, I. (1991). The theory of planned behavior. Organizational Behavior and Human Decision Processes, 50(2), 179-211.

Bagozzi, R. P. (1981). Attitudes, intentions, and behavior: A test of some key hypotheses. Journal of Personality and Social Psychology, 41(4), 607.

Bagozzi, R. P., Yi, Y., \& Phillips, L. W. (1991). Assessing construct validity in organizational research. Administrative Science Quarterly, 36(3), 421-458. 
Bian, X. (2006). An examination of factors influencing the formation of the consideration set and consumer purchase intention in the context of non-deceptive counterfeiting. Unpublished Doctoral dissertation, University of Glasgow, UK.

Bian, X. (2018). Do counterfeits only affect brands that are heavily counterfeited? New Insights. the Brand Protection Professional, 3(2), 20-22.

Bian, X., Haque, S., \& Smith, A. (2015). Social power, product conspicuousness, and the demand for luxury brand counterfeit products. British Journal of Social Psychology, 54(1), 37-54.

Bian, X., Wang, K. Y., Smith, A., \& Yannopoulou, N. (2016). New insights into unethical counterfeit consumption. Journal of Business Research, 69(10), 4249-4258.

Burroughs, J. E., \& Rindfleisch, A. (2002). Materialism and well-being: A conflicting values perspective. Journal of Consumer Research, 29(3), 348-370.

Churchill, G. A. (1999). Marketing research: Methodological foundations. Dryden Press.

Davidov, E., Schmidt, P., \& Schwartz, S. H. (2008). Bringing values back in: The adequacy of the European Social Survey to measure values in 20 countries. Public Opinion Quarterly, 72(3), 420-445.

de Matos, C. A., Ituassu, C. T., Rossi, C. A. V. (2007). Consumer attitudes toward counterfeits: a review and extension. Journal of Consumer Marketing, 24(1), 36-47.

Dietz, T., Kalof, L., Stern, P. C. (2002). Gender, values, and environmentalism. Social Science Quarterly, 83(1), 353-364.

Doran, C. J. (2009). The role of personal values in fair trade consumption. Journal of Business Ethics, 84(4), 549-563.

Fujita, K., Trope, Y., Liberman, N., Levin-Sagi, M. (2006). Construal levels and self-control. Journal of Personality and Social Psychology, 90(3), 351-367.

Grossman, G. M., \& Shapiro, C. (1988). Foreign counterfeiting of status goods. The Quarterly Journal of Economics, 103(1), 79-100.

Herstein, R., Drori, N., Berger, R., \& Barnes, B. R. (2015). Anticounterfeiting strategies and their influence on attitudes of different counterfeit consumer types. Psychology \& Marketing, 32(8), 842-859.

Hilton, M. (2003). Consumerism in twentieth-century Britain: The search for a historical movement. Cambridge University Press.

Krystallis, A., Vassallo, M., \& Chryssohoidis, G. (2012). The usefulness of Schwartz's 'values theory' in understanding consumer behaviour towards differentiated products. Journal of Marketing Management, 28(11-12), 1438-1463.

Le Roux, A., Thébault, M., \& Roy, Y. (2019). Do product category and consumers' motivations profiles matter regarding counterfeiting? Journal of Product \& Brand Management, 28(6), 758-770.

Manchiraju, S., \& Sadachar, A. (2014). Personal values and ethical fashion consumption. Journal of Fashion Marketing and Management, 18(3), 357-374.

Marticotte, F., \& Arcand, M. (2017). Schadenfreude, attitude and the purchase intentions of a counterfeit luxury brand. Journal of Business Research, 77, 175-183.

Muncy, J. A., \& Vitell, S. J. (1992). Consumer ethics: An investigation of the ethical beliefs of the final consumer. Journal of Business Research, 24(4), 297-311.

Nia, A., \& Zaichkowsky, J. L. (2000). Do counterfeits devalue the ownership of luxury brands? Journal of Product and Brand Management, 9(7), 485-497.

Penz, E., \& Stottinger, B. (2008). Original brands and counterfeit brands - do they have anything in common? Journal of Consumer Behaviour, 7, 146-163.

Perrea, T., Grunert, K., Krystallis, A., et al. (2014). Testing and validation of a hierarchical values-attitudes model in the context of green food in China. Asia Pacific Journal of Marketing and Logistics, 26(2), 296-314.

Roth, W. M., \& Jornet, A. (2014). Toward a theory of experience. Science Education, 98(1), 106-126.

Schwartz, S. H. (2003). A Proposal for Measuring Value Orientations across Nations. Questionnaire Package of the European Social Survey, 259(290), 261.

Schwartz, S. H. (2015). Basic individual values: Sources and consequences. In D. Sander \& T. Brosch (Eds.), Handbook of Value (pp. 63-84). Oxford University Press.

Schwartz, S. H., \& Bilsky, W. (1987). Toward a universal psychological structure of human values. Journal of Personality and Social Psychology, 53(3), 550-562.

Silvia, P. J. (2006). Exploring the psychology of interest 276. Oxford university Press.

Slepian, M. L., Masicampo, E. J., Ambady, N. (2015). Cognition from on high and down low: verticality and construal level. Journal of Personality and Social Psychology, 108(1), 1-17. 
Stringer, T., Mortimer, G., \& Payne, A. R. (2020). Do ethical concerns and personal values influence the purchase intention of fast-fashion clothing? Journal of Fashion Marketing and Management: An International Journal, 24(1), 99-120.

Stuppy, A., Mead, N., \& van Osselaer, S. M. J. (2020). I am, therefore i buy: Low self-esteem and the pursuit of self-verifying consumption. Journal of Consumer Research, 46(5), 956-973.

Trope, Y., \& Liberman, N. (2010). Construal-level theory of psychological distance. Psychological Review, 117(2), 440-463.

Wiedmann, K. P., Hennigs, N., \& Siebels, A. (2009). Value-based segmentation of luxury consumption behavior. Psychology and Marketing, 26(7), 625-651.

Wilcox, K., Kim, H. M., \& Sen, S. (2009). Why do consumers buy counterfeit luxury brands? Journal of Marketing Research, 46(2), 247-259.

Williams, R. M. (1979). Change and stability in values and value systems: A sociological perspective. In M. Rokeach (Ed.), Understanding human values: Individual and societal (pp. 15-46). Free Press.

Wong, D., Pugh, D., et al. (2001). Learning science: A Deweyan perspective. Journal of Research in Science Teaching, 38, 317-336.

Yoo, B., \& Lee, S. H. (2012). Asymmetrical effects of past experiences with genuine fashion luxury brands and their counterfeits on purchase intention of each. Journal of Business Research, 65(10), 1507-1515.

Zajonc, R. B. (1980). Feeling and thinking: Preferences need no inferences. American Psychologist, 35, $151-175$.

Publisher's note Springer Nature remains neutral with regard to jurisdictional claims in published maps and institutional affiliations. 